\title{
Ischemia-Reperfusion Injury and Regrowth of Liver Cancers: To Clamp or Not to Clamp?
}

\author{
Chetana Lim • Daniel Azoulay
}

Published online: 27 July 2014

(c) Springer Science+Business Media New York 2014

\begin{abstract}
Although resection remains the only potentially curative treatment for most patients with primary and secondary liver malignancies, the large majority of patients will experience recurrence. Factors reported to adversely affect the risk of local recurrence after surgery include tumor biology as well as surgical factors such as blood loss and transfusion during surgery. In this issue of Digestive Diseases \& Sciences, Orci et al. [1] discuss the relationship between hepatic ischemia-reperfusion injury and cancer recurrence. The authors have to be commended for their thoughtful analysis of the available data regarding this unresolved question.

Hepatic ischemia-reperfusion injury is an important cause of liver damage occurring during liver resection [2, 3] and during liver transplantation [4]. During liver surgery, hepatic pedicle clamping (the so-called Pringle Maneuver) efficiently reduces bleeding and transfusion during hepatic transection; intermittent occlusion of the inflow pedicle with intervals of reperfusion reduces this ischemia-reperfusion injury and the consequences of splanchnic congestion and therefore decreases injury to the liver parenchyma. In liver transplantation, the liver graft is particularly exposed to ischemia-reperfusion injury as a result of damage during organ procurement and frequent hemodynamic instability, preservation under cold ischemia, and graft reperfusion with a phase of warm ischemia between portal and arterial reperfusion.
\end{abstract}

\section{Lim · D. Azoulay $(\bowtie)$}

Service Chirurgie Digestive, Hépato-Bilio-Pancréatique et Transplantation Hépatique, Hôpital Henri Mondor, Assistance Publique Hôpitaux de Paris (AP-HP), 51 Avenue De Lattre

De Tassigny, 94010 Créteil, France

e-mail: daniel.azoulay@hmn.aphp.fr
It has been suggested, despite the lack of robust evidence, that ischemia-reperfusion per se is pro-tumorigenic. Although the exact mechanisms are still unclear, this might occur either through an upregulation of hypoxia-induced growth factors and cytokines, angiogenic factors, or inflammation [5, 6]. Moreover, the presence of underlying hepatic parenchymal injury such as steatosis might increase susceptibility of the liver to ischemia-reperfusion injury [7]. In this review, the authors present experimental and clinical data, indicating that hepatic ischemia-reperfusion injury increases the rate of cancer cell proliferation, analyzes how the ischemia process might promote tumor growth, and discusses a number of strategies to limit the negative effects of these injuries. The authors clearly state that extrapolation of data obtained from the rodent models described in this review should be applied cautiously to the results of clinical studies due to the numerous biases inherent to retrospectives series, as well as the limited number of patients studied.

Although the review is well written and balanced, it will likely raise several questions, since it is not a systematic review of the literature, but rather a narrative evaluation. Thus, some articles might have been omitted, especially those reporting negative results [8]. Since most of the studies focused on liver metastases from colorectal primaries and on hepatocellular carcinoma, there is concern that the underlying liver parenchymal injury was independently correlated with recurrence in several studies, suggesting the influence of potential confounders, such as cirrhosis or metabolic syndrome [9].

Although we agree that animal models provide strong data regarding the impact of liver clamping (and ischemiareperfusion) on the risks of recurrence, the heterogeneity in experimental study design combined with wide variations among experimental surgical procedures (e.g., duration of 
clamping, species) could adversely affect the interpretability of the data obtained.

Interestingly, several recent findings might add new insights to the issue. Our group has reported in a mouse model of colorectal liver metastases that hepatic ischemiareperfusion injury mobilized bone marrow-derived progenitor cells, making the liver tissue microenvironment more pro-angiogenic, which subsequently enhanced colorectal cancer cell engraftment and metastasis growth [10]. It is conceivable that all of these bone marrow-derived progenitor cells may participate in angiogenesis and vasculogenesis in tumors that recur after surgery, a supposition that can be tested experimentally.

In the clinic, the question still remains as to whether routine Pringle maneuver is justified. In our opinion to clamp or not to clamp systematically is not the right question: Surgeons must adapt to the situation in the operating room and clamp when needed relying on the old surgical adage "better clamping than bleeding."

\section{Conflict of interest None.}

\section{References}

1. Orci LA, Lacotte S, Oldani G, et al. The role of hepatic ischaemia-reperfusion injury and liver parenchymal quality on cancer recurrence. Dig Dis Sci. 2014. doi:10.1007/s10620-014-3182-7.
2. Azoulay D, Del Gaudio M, Andreani P, et al. Effects of 10 minutes of ischemic preconditioning of the cadaveric liver on the graft's preservation and function: the ying and the yang. Ann Surg. 2005;242:133-139.

3. Azoulay D, Lucidi V, Andreani P, et al. Ischemic preconditioning for major liver resection under vascular exclusion of the liver preserving the caval flow: a randomized prospective study. $J \mathrm{Am}$ Coll Surg. 2006;202:203-211.

4. Zhai Y, Petrowsky H, Hong JC, et al. Ischaemia-reperfusion injury in liver transplantation-from bench to bedside. Nat Rev Gastroenterol Hepatol. 2012;10:79-89.

5. Tamagawa K, Horiuchi T, Uchinami M, et al. Hepatic ischemiareperfusion increases vascular endothelial growth factor and cancer growth in rats. J Surg Res. 2008;148:158-163.

6. van der Bilt JD, Soeters ME, Duyverman AM, et al. Perinecrotic hypoxia contributes to ischemia/reperfusion-accelerated outgrowth of colorectal micrometastases. Am J Pathol. 2007;170: 1379-1388.

7. Chu MJ, Hickey AJ, Phillips AR, Bartlett AS. The impact of hepatic steatosis on hepatic ischemia-reperfusion injury in experimental studies: a systematic review. Biomed Res Int. 2013; 2013:192029.

8. Weiss MJ, Ito $\mathrm{H}$, Araujo RL, et al. Hepatic pedicle clamping during hepatic resection for colorectal liver metastases: no impact on survival or hepatic recurrence. Ann Surg Oncol. 2012;20: 285-294.

9. Cauchy F, Zalinski S, Dokmak S, et al. Surgical treatment of hepatocellular carcinoma associated with the metabolic syndrome. Br J Surg. 2012;100:113-121.

10. Lim C, Broqueres-You D, Brouland JP, et al. Hepatic ischemiareperfusion increases circulating bone marrow-derived progenitor cells and tumor growth in a mouse model of colorectal liver metastases. J Surg Res. 2013;184:888-897. 